\title{
Performance Analysis of Adaptive Fuzzy Sliding Mode for Nonlinear Control of the Doubly Fed Induction Motor
}

\author{
Djamila Cherifi, Yahia Miloud \\ Department of Electrical Engineering, Dr. Moulay Tahar University, Algeria
}

\begin{tabular}{l} 
Article Info \\
\hline Article history: \\
Received Jul 30, 2018 \\
Revised Des 4, 2018 \\
Accepted Dec 18, 2018 \\
\hline
\end{tabular}

\section{Keyword:}

Adaptive Fuzzy Sliding Mode Controller (AFSMC)

Classical Regulator

Doubly Fed Induction Motor (DFIM)

Variable Structure Control

(Sliding Mode)

Vector-Control

\begin{abstract}
In this article, we propose a contribution to the control of a doubly fed induction motor by sliding mode with adaptive fuzzy logic. The technique of vector-control by classical field oriented applied to the doubly fed induction motor (DFIM) with mechanical sensors made it possible to have performances comparable with that of the direct current motor. However, it very sensitive to the parametric variations of the machine. The regulation speed by a classical regulator (PI) presents disadvantages: Poor robustness against parametric uncertainties of modeling and no the considering of the disturbances and little degree of freedom for the regulation. Because this effect, several robust controls were proposed in the technical literature to ensure the decoupling of the currents of the DFIM in a reference $(d, q)$ leading to calculate simplified correctors. Among them, the variable structure control by sliding mode. It uses algorithms of regulations which ensure the robustness of the behavior of the process compared to the parametric variations and disturbances. Also, the impact of regulators based on artificial intelligence techniques such as adaptive fuzzy sliding mode controller are studied. In terms of results obtained, good dynamic performance and robustness with respect to load disturbances and parametric variation has been observed.
\end{abstract}

Copyright (ㅇ 2018 Institute of Advanced Engineering and Science. All rights reserved.

\section{Corresponding Author:}

Djamila Cherifi,

Department of Electrical Engineering,

Dr. Moulay Tahar University,

Saida, 20000. Algeria.

Email: d_cherifi@yahoo.fr

\section{INTRODUCTION}

In the field of high-power drives (such as the rolling mill for example), there is a new and original solution, using an alternative machine operating in a mode. This is the doubly fed induction motor DFIM, [1], [2] where the stator is fed by a fixed network and the rotor by variable power supply which can be a voltage source or a power source, [3].

DFIM finds its application in high power drives, it is characterized by its robustness, its longevity and a wider range of speed variation (hypo-synchronous, synchronous and hyper-synchronous regime) However, the asynchronous machine has a major disadvantage: the structure dynamic is strongly non-linear and the existence of a strong coupling between the torque and the flux, which complicates its control [4], [5].

In order to obtain a dual power asynchronous machine whose performances are like a DC machine, it is necessary to ensure the decoupling between the flux and the electromagnetic torque. This is the idea of the appearance of the vector control technique, or the control by flux orientation, [6]. This technique was proposed in 1973 by Blaschke and Hasse. The purpose of this technique is to manage the asynchronous machine as an independent excitation DC machine where there is a natural decoupling between the magnitude controlling the flux (the excitation current) and that related to the torque (the armature current) [7], [8]. 
Conventional PI or PID control techniques cover a wide range in industrial applications. These are linear control techniques and have the advantage of simplicity of implementation and ease of synthesis. Over time, its applications will be inefficient, especially if the processes to be controlled have complex and nonlinear structures. Finding the substitute for these classic techniques is the concern of many researchers. Because the latter involves a compromise between the robustness of one side and the cost of another side [9], [10].

Sliding mode control, which was developed in the Soviet Union there are more than 30 years old, is a nonlinear control technique. It uses setting algorithms which ensure the robustness of the behavior of the process in relation to the variations parametric and disturbances. It has several advantages such as: Robustness, speed of response without exceeding and good efficiency at parametric and modeling uncertainties. However residual vibrations at high frequencies inherent or chattering to order remain considerable inconvenience, [11]-[13].

In order to eliminate the chattering [14], as it can damage the actuators by oscillations too frequent and affect the operation and performance of the system, it is proposed the application of fuzzy logic in sliding mode, [15], [16] for adjusting the speed of the DFIM.

This paper will be organized as follows. Section II dynamic model of DFIM and stator flux orientation will be reported; principle of Sliding mode control will be given in Section III, as well as the proposed solution will be presented. In Section IV, results of simulation tests are reported. Concluding remarks will be given in section $\mathrm{V}$.

\section{DOUBLY FED INDUCTION MACHINE MODEL}

By referring to a rotating reference frame, denoted by the superscript $(d, q)$, the dynamic model of a DFIM can be expressed by, [1]:

$$
\left\{\begin{array}{l}
\frac{d i_{s d}}{d t}=-a_{1} i_{s d}+\left(a \omega+\omega_{s}\right) i_{s q}+a_{3} i_{r d}+a_{5} \omega i_{r q}+b_{1} v_{s d}-b_{3} v_{r d} \\
\frac{d i_{s q}}{d t}=-\left(a \omega+\omega_{s}\right) i_{s d}-a_{1} i_{s q}-a_{5} \omega i_{r d}+a_{3} i_{r q}+b_{1} v_{s q}-b_{3} v_{r q} \\
\frac{d i_{r d}}{d t}=a_{4} i_{s d}-a_{6} \omega i_{s q}-a_{5} \omega i_{r d}+\left(\omega_{s}-\frac{\omega}{\sigma}\right) i_{r q}-b_{3} v_{s d}+b_{2} v_{r d} \\
\frac{d i_{r q}}{d t}=-a_{6} \omega i_{s d}-a_{4} i_{s q}-\left(\omega_{s}-\frac{\omega}{\sigma}\right) i_{r d}-a_{5} \omega i_{r q}-b_{3} v_{s q}+b_{2} v_{r q} \\
\frac{d \Omega}{d t}=\frac{1}{J} T_{e m}-\frac{f}{J} \Omega-\frac{1}{J} T_{r}
\end{array}\right.
$$

where:

$$
\begin{gathered}
a=\frac{1-\sigma}{\sigma}, a_{1}=\frac{R_{s}}{\sigma L_{s}}, a_{2}=\frac{R_{r}}{\sigma L_{r}}, a_{3}=\frac{R_{r} M}{\sigma L_{r} L_{s}}, a_{4}=\frac{R_{s} M}{\sigma L_{s} L_{r}}, a_{5}=\frac{M}{\sigma L_{s}}, a_{6}=\frac{M}{\sigma L_{r}}, \\
b_{1}=\frac{1}{\sigma L_{s}}, b_{2}=\frac{1}{\sigma L_{r}}, b_{3}=\frac{M}{\sigma L_{s} L_{r}}, \sigma=1-\frac{M^{2}}{L_{s} L_{r}}
\end{gathered}
$$

To simplify the control, it is necessary to make a judicious choice of reference. For this, one places oneself in a reference frame $(\mathrm{d}-\mathrm{q})$ linked to the rotating field with an orientation of the stator flux (the axis $\mathrm{d}$ aligned with the direction of the stator flux), as the following Figure 1 shows, [17].

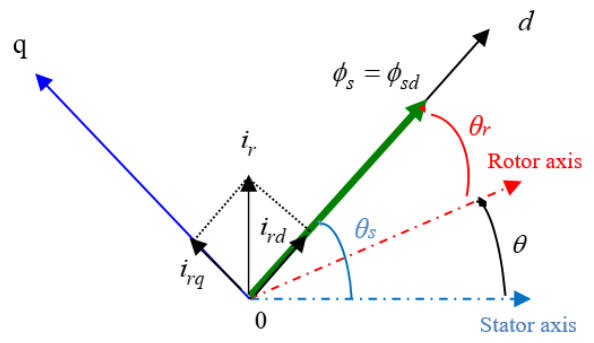

Figure 1. Stator field orientation on the d-axis 
We obtain

$\phi_{s d}=\phi_{s}$ and $\phi_{s q}=0$

The fluxes are given by:

$\left\{\begin{array}{l}\phi_{s d}=L_{s} i_{s d}+M i_{r d} \\ \phi_{s q}=L_{s} i_{s q}+M i_{r q} \\ \phi_{r d}=L_{r} i_{r d}+M i_{s d} \\ \phi_{r q}=L_{r} i_{r q}+M i_{s q}\end{array}\right.$

We obtain:

$\left\{\begin{array}{l}i_{s d}=\frac{1}{L_{s}}\left(\phi_{s d}-M \cdot i_{r d}\right) \\ i_{s q}=\frac{1}{L_{s}}\left(\phi_{s q}-M \cdot i_{r q}\right)\end{array}\right.$

The electromagnetic torque is expressed by:

$T_{e m}=\frac{p M}{L_{s}}\left(\phi_{s q} i_{r d}-\phi_{s d} i_{r q}\right)$

Replacing (2) in (3) and (5) we find:

$$
T_{e m}=\frac{p M}{L_{s}}\left(-\phi_{s} i_{r q}\right)=-\frac{p M}{L_{s}} \phi_{s} i_{r q}
$$

and

$$
\left\{\begin{array}{l}
\phi_{s q}=0 \Rightarrow i_{s q}=-\frac{M}{L_{s}} i_{r q} \\
i_{s d}=0 \\
i_{r d}=\frac{\phi_{s}^{*}}{M}
\end{array}\right.
$$

from $(6)$

$$
\begin{aligned}
& i_{r q}=-\frac{L_{s}}{p M} \frac{T_{e m}^{*}}{\phi_{s}^{*}} \\
& \frac{d \theta_{s}}{d t}=\omega_{s}=\frac{\left(\frac{R_{s} \cdot M}{L_{s}} i_{r q}+V_{s q}\right)}{\phi_{s}^{*}}
\end{aligned}
$$

after arrangement we will have the following system:

$$
\begin{aligned}
& \frac{d i_{r d}}{d t}=-\frac{1}{\sigma}\left(\frac{1}{T_{r}}+\frac{M^{2}}{L_{s} T_{s} L_{r}}\right) i_{r d}-\frac{M}{\sigma L_{s} L_{r}} V_{s d}+\frac{M}{\sigma L_{s} L_{r} T_{s}} \phi_{s d}+\left(\omega_{s}-\omega\right) i_{r q}+\frac{1}{\sigma L_{r}} v_{r d} \\
& \frac{d i_{r q}}{d t}=-\frac{1}{\sigma}\left(\frac{1}{T_{r}}+\frac{M^{2}}{L_{s} T_{s} L_{r}}\right) i_{r_{r q}}-\frac{M}{\sigma L_{s} L_{r}} V_{s q}+\frac{M}{\sigma L_{s} L_{r}} \omega \phi_{s d}+\left(\omega_{s}-\omega\right) i_{r d}+\frac{1}{\sigma L_{r}} v_{r q} \\
& \frac{d \phi_{s d}}{d t}=V_{s d}+\frac{M}{T_{s}} i_{r d}-\frac{1}{T_{s}} \phi_{s d} \\
& \frac{d \phi_{s q}}{d t}=V_{s q}+\frac{M}{T_{s}} i_{r q}-\omega_{s} \phi_{s d} \\
& \frac{d \Omega}{d t}=-\frac{p M}{J L_{s}}\left(\phi_{s d} i_{r q}\right)-\frac{f}{J} \Omega-\frac{1}{J} T_{r}
\end{aligned}
$$


with: $T_{r}=\frac{L_{r}}{R_{r}} ; T_{s}=\frac{L_{s}}{R_{s}}$

The flux estimator can be obtained by the following (11):

$$
\begin{aligned}
& \phi_{s d}=L_{s} i_{s d}+M i_{r d} \\
& \phi_{s q}=L_{s} i_{s q}+M i_{r q}
\end{aligned}
$$

The position stator flux is calculated by the following equations: $\theta_{r}=\theta_{s}-\theta$

where $\theta_{s}=\int \omega_{s} d t, \theta=\int \omega d t, \omega=P \Omega . \theta_{s}$ is the electrical stator position, $\theta$ is the electrical rotor position.

\section{PRINCIPLE OF SLIDING MODE CONTROL}

A Sliding Mode Controller (SMC) is a Variable Structure Controller (VSC). Basically, a VSC includes several different continuous functions that can map plant state to a control surface. As a result, the sliding mode control is based on three steps [18].

\subsection{Choice of the switching surface}

J. Slotine proposes a form of general equation to determine the sliding surface

$$
\begin{aligned}
& S(x)=\left(\frac{d}{d t}+\lambda\right)^{n-1} e(x) \\
& e(x)=x_{r e f}-x
\end{aligned}
$$

$e(x):$ denotes the error of the controlled greatness;

$\lambda$ : Positive coefficient;

$n$ : Relative degree;

$x_{\text {ref }}:$ Reference greatness.

\subsection{The condition of convergence}

The condition of convergence is defined by the equation of Lyapunov.

$$
S(x) \cdot \dot{S}(x)<0
$$

\subsection{Control Calculation}

The control algorithm includes two terms, the first for the exact linearization, the second discontinuous one for the system stability.

$$
u=u^{e q}+u^{n}
$$

$u^{e q}$ : corresponds to the equivalent order suggested by Utkin (1992). It is calculated starting from the expression:

$$
\dot{S}(x)=0
$$

$u^{n}$ is given to guarantee the attractivity of the variable to be controlled towards the commutation surface.

The simplest equation is the form of relay.

$$
u^{n}=k \text { sat } S(x)
$$

$k$ is the controller gain.

\subsection{Speed control}

Performance Analysis of Adaptive Fuzzy Sliding Mode for Nonlinear Control ... (Djamila Cherifi) 
The speed error is defined by:

$$
e=\Omega_{r e f}-\Omega
$$

for $n=1$, the speed control manifold equation can be obtained by:

$$
\begin{aligned}
& S(\Omega)=e=\Omega_{r e f}-\Omega \\
& \dot{S}(\Omega)=\dot{\Omega}_{r e f}-\dot{\Omega}
\end{aligned}
$$

substituting the expression of $\dot{\Omega}$ in (10) and in (20), we obtain:

$$
\dot{S}(\Omega)=\dot{\Omega}_{r e f}-\left(-\frac{p M}{J L_{s}}\left(\phi_{s d} i_{r q}\right)-\frac{f}{J} \Omega-\frac{1}{J} T_{r}\right)
$$

we take:

$$
i_{r q}=i_{r q}^{e q}+i_{r q}^{n}
$$

during the sliding mode and in permanent regime, we have:

$$
S(\Omega)=0, \dot{S}(\Omega)=0, i_{r q}^{n}=0
$$

the equivalent control is:

$$
i_{r q}^{e q}=-\frac{J L_{s}}{P M \phi_{s d}}\left(\dot{\Omega}_{r e f}+\frac{C_{r}}{J}+\frac{f}{J} \Omega\right)
$$

where the correction factor is given by:

$$
i_{r q}^{n}=K_{i_{r q}} \operatorname{sat}(S(\Omega))
$$

In our proposal which allows the combination between the fuzzy logic and the control by sliding mode, we call the controller resulting from this combination: controller by fuzzy sliding mode (FSMC), it has the same control law as the SMC set to apart from the parameters $k$ and $\xi$ the component $u^{n}$ that will be adapted by a system to a fuzzy inference.

The key idea of this combination is inspired by the fact that in the ideal case and when $S(x)$ is far from the sliding surface, parameters $k$ and $\xi$ must have a large enough value and when $S(x)$ is near of the sliding surface, adjusted parameters $k$ and $\xi$ must have a small value.

In this voice one can propose an adaptation of these parameters by means of a system with a fuzzy inference while keeping the same laws of control of the controller SMC.

$S(x)$ in our case represents the input space of the fuzzy system composed of two terms $S$ and $\dot{S}$, the gain adjustment $k$ and the parameter $\xi$ are written in the form of the following fuzzy rule:

$$
\text { If } \mathrm{S}(\mathrm{t}) \text { is } \mathrm{A}_{\mathrm{j}} \text { Then } k \text { and } \xi \text { are } \mathrm{B}_{\mathrm{j}}
$$

where $\mathrm{j}=1, \ldots ., \mathrm{m}$ and $\mathrm{m}$ represent the total number of rules.

The terms $k$ and $\xi$ are therefore adapted by a fuzzy adapter having two inputs " $\varepsilon$ " and " $\Delta \varepsilon$ " of three membership functions and an ' $\alpha$ ' output of nine membership functions which are represented in Figure 2 and Figure 3 respectively. A typical rule reads as follows, as shown in Table 1. 


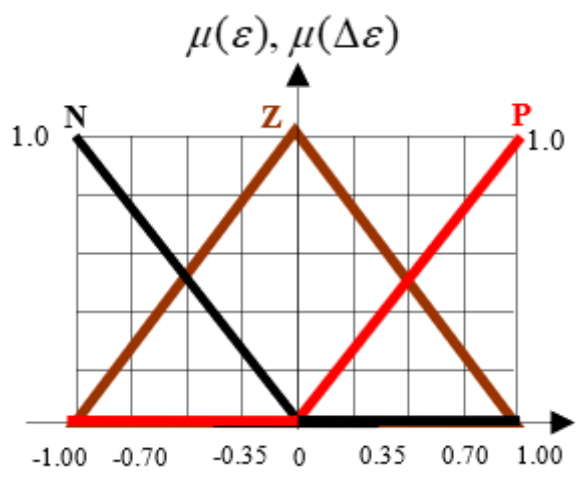

Figure 2. The inputs membership functions of the AFSMC

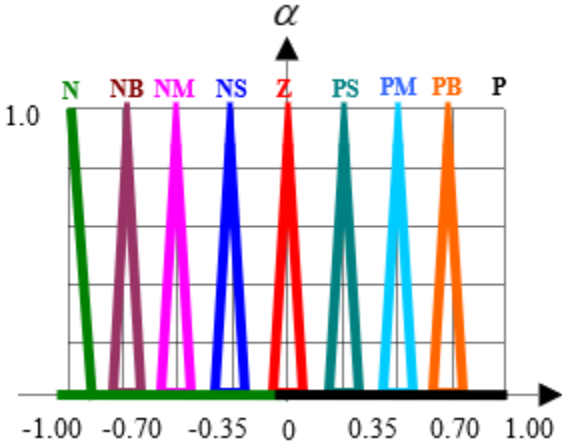

Figure 3. The output membership functions of the AFSMC

Table 1. A typical rule reads as follows:

\begin{tabular}{cccc}
\hline Symbol & Mean & Symbol & Mean \\
\hline $\mathrm{N}$ & Negative & $\mathrm{P}$ & Positive \\
$\mathrm{Z}$ & Zero & NB & Negative Big \\
NS & Negative Small & NM & Negative Medium \\
PS & Positive Small & PM & Positive Medium \\
PB Positive Big & & & \\
\hline
\end{tabular}

therefore, the discontinuous control law of (24) becomes:

$$
i_{r q n}^{f l}=k_{\Omega}^{f l} \operatorname{sat}\left(s(\Omega) / \xi_{\Omega}^{f l}\right)
$$

with

$$
\left\{\begin{array}{l}
k_{\Omega}^{f l}=\alpha k_{\Omega} \\
\xi_{\Omega}^{f l}=\alpha \xi_{\Omega}
\end{array}\right.
$$

For the control law of (26), we will see in a transient state a series of values of $k_{\Omega}^{f l}$ and $\xi_{\Omega}^{f l}$, which gives an infinite number of $\operatorname{sat}\left(s(\Omega) / \xi_{\Omega}^{f l}\right)$ functions. In steady state, the magnitude $\alpha$ takes the value '1'. The result of defuzzifying the command for an entry $S(x)$ is presented as shown in Figure 4.

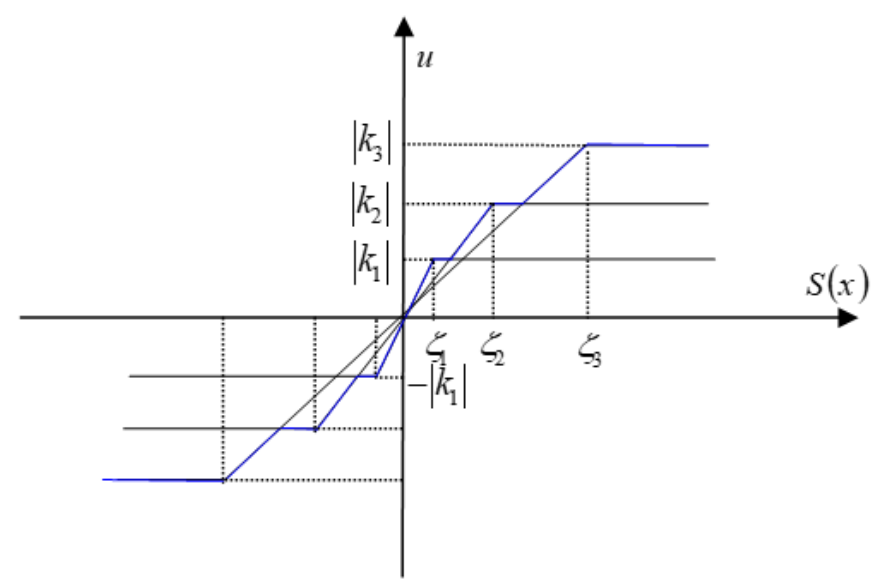

Figure 4. Control signal of the fuzzy-sliding controller 
The rules governing the gain adaptation law and the parameter are presented as follows:

\begin{tabular}{|l|l|l|l|l|l|l|l|}
\hline $\mathbf{R}_{1}:$ if & $\boldsymbol{S}$ & is & $\mathrm{P}$ and $\dot{\boldsymbol{S}}$ is & $\mathrm{P}$ then & $\alpha$ & is & $\mathrm{N} ;$ \\
\hline $\mathbf{R}_{2}:$ if & $\boldsymbol{S}$ & is & $\mathrm{P}$ and $\dot{\boldsymbol{S}}$ is & $\mathrm{Z}$ then & $\alpha$ & is & $\mathrm{NB} ;$ \\
\hline $\mathbf{R}_{3}:$ if & $\boldsymbol{S}$ & is & $\mathrm{P}$ and $\dot{\boldsymbol{S}}$ is & $\mathrm{N}$ then & $\alpha$ & is & $\mathrm{NM} ;$ \\
\hline $\mathbf{R}_{4}:$ if & $\boldsymbol{S}$ & is & $\mathrm{Z}$ and $\dot{\boldsymbol{S}}$ is & $\mathrm{P}$ then & $\alpha$ & is & $\mathrm{NS} ;$ \\
\hline $\mathbf{R}_{5}:$ if & $\boldsymbol{S}$ & is & $\mathrm{Z}$ and $\dot{\boldsymbol{S}}$ is & $\mathrm{Z}$ then & $\alpha$ & is & $\mathrm{ZE} ;$ \\
\hline $\mathbf{R}_{6}:$ if & $\boldsymbol{S}$ & is & $\mathrm{Z}$ and $\dot{\boldsymbol{S}}$ is & $\mathrm{N}$ then & $\alpha$ & is & $\mathrm{PS} ;$ \\
\hline $\mathbf{R}_{7}:$ if & $\boldsymbol{S}$ & is & $\mathrm{N}$ and $\dot{\boldsymbol{S}}$ is & $\mathrm{P}$ then & $\alpha$ & is & $\mathrm{PM} ;$ \\
\hline $\mathbf{R}_{8}:$ if & $\boldsymbol{S}$ & is & $\mathrm{N}$ and $\dot{\boldsymbol{S}}$ is & $\mathrm{Z}$ then & $\alpha$ & is & $\mathrm{PB} ;$ \\
\hline $\mathbf{R}_{9}:$ if & $\boldsymbol{S}$ & is & $\mathrm{N}$ and $\dot{\boldsymbol{S}}$ is & $\mathrm{N}$ then & $\alpha$ & is & $\mathrm{P}$ \\
\hline
\end{tabular}

\subsection{Rotor direct current control and limitation}

In order to limit all possible overshoot of the current $i_{r d}$, we add a limiter of current defined by:

$$
i_{r d}^{\lim }=i_{r d}^{\max } \operatorname{sat}\left(i_{r d}\right)
$$

The direct current error is defined by:

$$
e=i_{r d}^{\lim }-i_{r d}
$$

for $n=1$, the direct current control manifold equation can be obtained by:

$$
\begin{aligned}
& S\left(i_{r d}\right)=i_{r d}^{\lim }-i_{r d} \\
& \dot{S}\left(i_{r d}\right)=i_{r d}^{\lim }-\dot{i}_{r d}
\end{aligned}
$$

Substituting the expression of $\dot{i}_{r d}$ in (10) and in (30), we obtain:

$$
\dot{S}\left(i_{r d}\right)=i_{r d}^{\lim }-\left(-\frac{1}{\sigma}\left(\frac{1}{T_{r}}+\frac{M^{2}}{L_{s} \cdot T_{s} \cdot L_{r}}\right) i_{r d}-\frac{M}{\sigma L_{r} L_{s}} V_{s d}+\frac{M}{\sigma L_{r} L_{s} T_{s}} \phi_{s d}+\left(\omega_{s}-\omega\right) i_{r q}+\frac{1}{\sigma L_{r}} V_{r d}\right)
$$

The control voltage $V_{r d}^{r e f}$ is defined by

$$
V_{r d}^{r e f}=V_{r d}^{e q}+V_{r d}^{n}
$$

during the sliding mode and in permanent regime, we have:

$$
S\left(i_{r d}\right)=0, \dot{S}\left(i_{r d}\right)=0, V_{r d}^{n}=0
$$

where the equivalent control is:

$$
V_{r d}^{e q}=\left(i_{r d}^{\lim }+\frac{1}{\sigma}\left(\frac{1}{T_{r}}+\frac{M^{2}}{L_{s} \cdot T_{s} \cdot L_{r}}\right) i_{r d}+\frac{M}{\sigma L_{r} L_{s}} V_{s d}-\frac{M}{\sigma L_{r} L_{s} T_{s}} \phi_{s d}-\left(\omega_{s}-\omega\right) i_{r q}\right) \sigma L_{r}
$$


substituting $i_{r d}=\frac{\phi_{s}^{*}}{M}$ in $(23)$

$$
V_{r d}^{e q}=\left(i_{r d}^{\lim }+\frac{1}{\sigma T_{r}} i_{r d}-\frac{M}{\sigma L_{r} L_{s}} V_{s d}-\left(\omega_{s}-\omega\right) i_{r q}\right) \sigma L_{r}
$$

therefore, the correction factor is given by:

$$
V_{r d}^{n}=K_{V_{r d}} \operatorname{sat}\left(S\left(i_{r d}\right)\right)
$$

where $K_{V_{r d}}$ :positive constant

\subsection{Rotor quadrature current control and limitation}

In order to limit all possible overshoot of the current $i_{r d}$, we add a limiter of current defined by:

$$
i_{r q}^{\lim }=i_{r q}^{\max } \operatorname{sat}\left(i_{r q}\right)
$$

the direct current error is defined by:

$$
e=i_{r q}^{\lim }-i_{r q}
$$

for $n=1$, the direct current control manifold equation can be obtained by:

$$
\begin{aligned}
& S\left(i_{r q}\right)=i_{r q}^{\lim }-i_{r q} \\
& \dot{S}\left(i_{r q}\right)=i_{r q}^{\lim }-\dot{i}_{r q}
\end{aligned}
$$

Substituting the expression of $\dot{i}_{r q}$ equation (10) in equation (39), we obtain:

$$
\dot{S}\left(i_{r q}\right)=i_{r q}^{\lim }-\left(-\frac{1}{\sigma}\left(\frac{1}{T_{r}}+\frac{M^{2}}{L_{s} \cdot T_{s} \cdot L_{r}}\right) i_{r q}-\frac{M}{\sigma L_{r} L_{s}} V_{s q}+\frac{M}{\sigma L_{r} L_{s}} \omega_{s} \phi_{s d}-\left(\omega_{s}-\omega\right) i_{r d}+\frac{1}{\sigma L_{r}} V_{r q}\right)
$$

the control voltage $V_{r q}^{r e f}$ is defined by

$$
V_{r q}^{r e f}=V_{r q}^{e q}+V_{r q}^{n}
$$

during the sliding mode and in permanent regime, we have:

$$
S\left(i_{r q}\right)=0, \dot{S}\left(i_{r q}\right)=0, V_{r q}^{n}=0
$$

where the equivalent control is:

$$
V_{r q}^{e q}=\left(i_{r q}^{\lim }+\frac{1}{\sigma}\left(\frac{1}{T_{r}}+\frac{M^{2}}{L_{s} \cdot T_{s} \cdot L_{r}}\right) i_{r q}+\frac{M}{\sigma L_{r} L_{s}} V_{s q}-\frac{M}{\sigma L_{r} L_{s}} \omega_{s} \phi_{s d}+\left(\omega_{s}-\omega\right) i_{r q}\right) \sigma L_{r}
$$

therefore, the correction factor is given by:

$$
V_{r q}^{n}=K_{V_{r q}} \operatorname{sat}\left(S\left(i_{r q}\right)\right)
$$

where $K_{V_{r q}}$ :positive constant 


\subsection{Stator flux control}

In the proposed control, the manifold equation can be obtained by:

$$
\begin{aligned}
& S\left(\phi_{s d}\right)=\phi_{s d}^{r e f}-\phi_{s d} \\
& \dot{S}\left(\phi_{s d}\right)=\dot{\phi}_{s d}^{r e f}-\dot{\phi}_{s d}
\end{aligned}
$$

Substituting the expression of $\phi_{s d}$ equation (10) in equation (45), we obtain:

$$
\dot{S}\left(\phi_{s d}\right)=\dot{\phi}_{s d}^{r e f}-\left(V_{s d}+\frac{M}{T_{s}} i_{r d}-\frac{1}{T_{s}} \phi_{s d}\right)
$$

the control voltage $i_{r d}$ is defined by

$$
i_{r d}=i_{r d}^{e q}+i_{r d}^{n}
$$

during the sliding mode and in permanent regime, we have:

$$
S\left(\phi_{s d}\right)=0, \dot{S}\left(\phi_{s d}\right)=0, i_{r d}^{n}=0
$$

The equivalent control is:

$$
i_{r d}^{e q}=\left(\dot{\phi}_{s d}^{r e f}-V_{s d}+\frac{1}{T_{s}} \phi_{s d}\right) \frac{M}{T_{s}}
$$

where the correction factor is given by:

$$
i_{r d}^{n}=K_{i_{r d}} \operatorname{sat}\left(S\left(i_{r d}\right)\right)
$$

where $K_{i_{r d}}$ :positive constant

\section{RESULTS AND ANALYSIS}

To evaluate the performance of the proposed method, the model for the control law applied to the DFIM Figure 5 has been implemented in the Matlab / Simulink software.

The simulation results illustrate the dynamic responses of the rotor speed, the electromagnetic torque, the components of the stator fluxes and the rotor current.

The motor is operated at $\Omega_{\mathrm{ret}}=150 \mathrm{rad} / \mathrm{s}$ under no load and a load disturbance torque (10 N.m) is suddenly applied at $\mathrm{t}=1 \mathrm{~s}$ and eliminated at $\mathrm{t}=2 \mathrm{~s}(-10 \mathrm{~N} . \mathrm{m})$, To show the effect of the parameters uncertainties, we have simulated the system with $+50 \%$ of value of the rotor resistance and compared to nominal value.

This Figure 6 shows the dynamic response of the speed. The latter reaches its reference in a response time of $0.13 \mathrm{~s}$. The introduction of charge has no influence on the evolution (stability) of the speed, which shows the robustness of the proposed control against these disturbances. It is also noted that the speed follows its setpoint rapidly during the reverse direction of rotation (identical to the response time at startup).

It can also be seen that increasing the rotor resistance $\mathrm{R}_{\mathrm{r}}$ by $+50 \%$ of its nominal value does not cause any undesirable effects. 


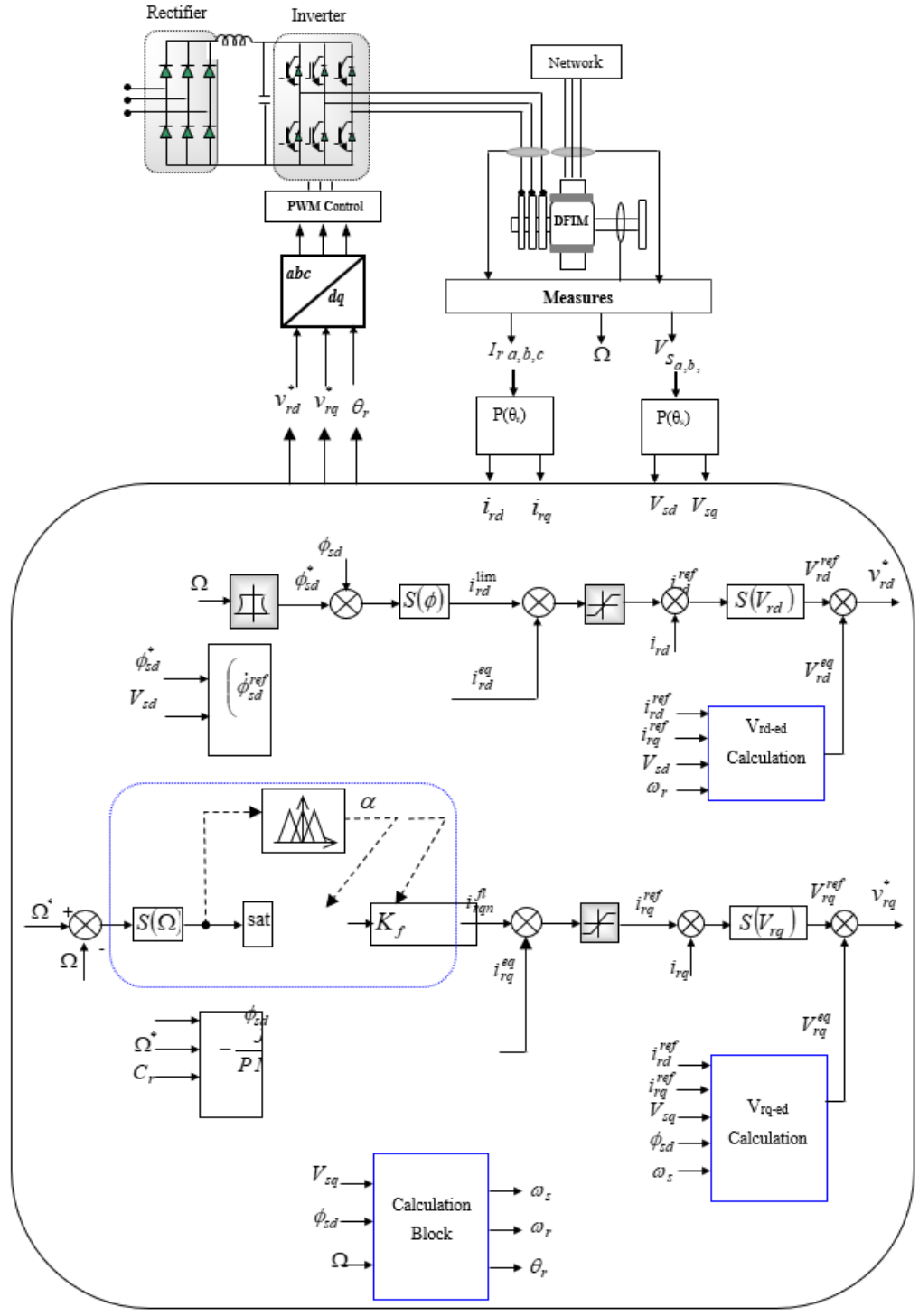

Figure 5. Non-Linear Control scheme for DFIM using the Adaptive Fuzzy Sliding Mode controller

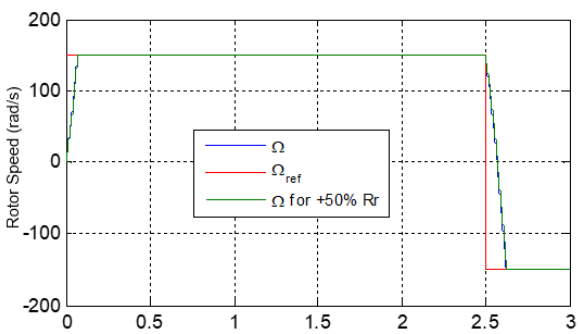

Figure 6. The performance of the rotor speed for DFIM using the Adaptive Fuzzy Sliding Mode controller

The simulation reported in Figure 7 shows that the direct component of the stator flux stabilizes at the value of the steady state reference stator flux while its quadrature component stabilizes at zero ( $\left.\phi_{s d}=\phi_{\text {ref }}, \phi_{s q}=0\right)$.

During the rotation inversion the change of the direction of the torque does not degrade the orientation of the flux so the introduction of charge has no influence, and it is clearly seen that the decoupling is not influenced by the variation of $R_{r}$. 
Figure 8 illustrates the dynamic response of the electromagnetic torque for two rotor resistance values $\left(R_{r n}\right.$ and $+50 \%$ of $\left.R_{r}\right)$. Given this result, we note that this command gives good performance. It is noted that the regulation of the two rotor currents by sliding mode Figure 9 gives faster responses during a vacuum start and more robust during the variation of the load and the rotor resistance.

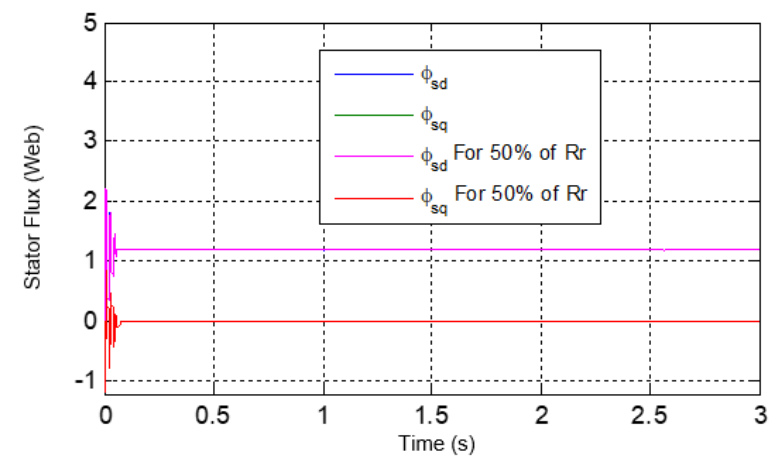

Figure 7. The performance of the stator flux for DFIM Sliding Mode controller

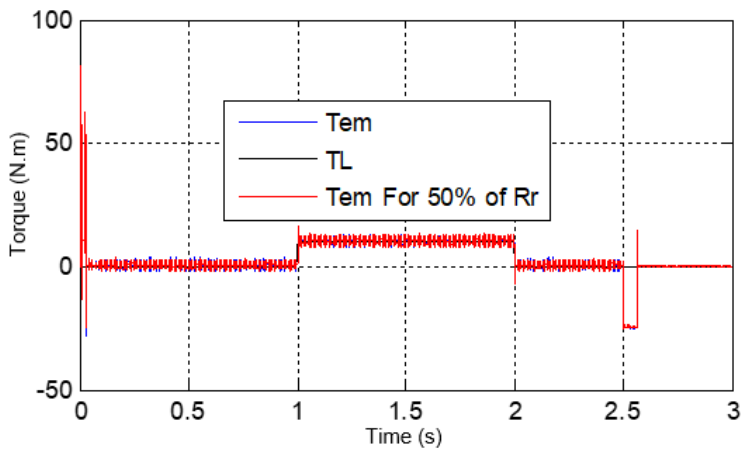

Figure 8 . The performance of the torque for DFIM

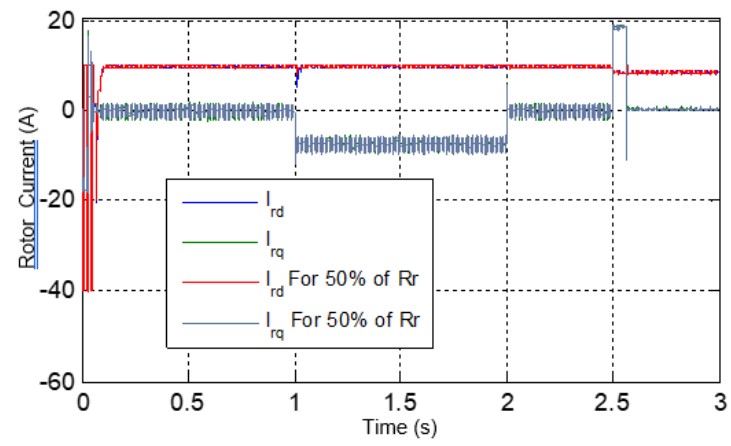

Figure 9. The performance of the rotor current for DFIM using Sliding Mode controller

From the results obtained, all the tests applied to this control plus the variation of the rotor resistance does not cause any undesirable effect on all the dynamic responses, and this shows the robustness of the nonlinear control applied to the DFIM.

Finally, and after this detailed study, we note a significant improvement in the static and dynamic performance of the DFIM, which is proving the efficiency and robustness of the developed Adaptive Fuzzy Sliding Mode controller and the nonlinear control chosen compared to the classic PI controller developed in [19], [20] 


\section{CONCLUSION}

This paper was the subject of the application of the sliding mode controller in the following control loops: stator flux and rotor currents on the Doubly Fed Induction Motor (DFIM) and it is applied Adaptive Fuzzy Sliding Mode controller only in the speed loop.

in this context, we first presented a theoretical reminder on the sliding mode control of variable structure systems, then we approached the adaptive fuzzy control algorithm with its different steps, then applied it on the regulation of DFIM, and finally simulation results are presented and commented.

It can be concluded from these results that, the field-oriented control using a non-linear Fuzzysliding mode is more robust than that of conventional regulator-controlled vector control (IP or PI). The comparative study in the test results by speed reference variation and rotor resistance variation shows that the robustness quality of the proposed controller.

\section{REFERENCES}

[1] Salloum Georges, Ghosn Ragi, Pietrzak-David Maria, De Fornel Bemard, "A Comparison of Sensorless Speed Estimation for a Doubly Fed Induction Machine", EPE 2005.

[2] S. Drid, M. Tadjine, M.S. Nait-Said, "Nonlinear feedback control and torque optimization of a doubly fed induction motor," Journal of Electrical Engineering, vol. 56(3-4), pp. 57-63, 2005.

[3] Y. Bekakra, D. Ben Attous, "Comparison between Fuzzy Sliding Mode and Traditional IP Controllers in a Speed Control of a Doubly Fed Induction Motor," Ecti Transactions on Electrical ENG., Electronics, and Communications, vol.10(2), Aug 2012.

[4] P.E. Vidal, D. Pietrzak and M. B. de Fornel, "Stator Flux Oriented Control of a Doubly Fed Induction Machine," $10^{\text {th }}$ European Conference on Power Electronics and Applications, Toulouse, France, pp. 1- 9, 2003.

[5] Sejir Khojet El Khil, Ilhem Slama-Belkhodja, Maria Pietrzak, David Bernard de Fornel, "Design of rotor and stator converters for a Double Fed Induction Machine," IEEE ISIE 2006, Montreal, Quebec, Canada, Jul 2006.

[6] E. Blaschke, "The principe of field orientation as applied to the new transvector closedloop control system for rotating field machine," Siemens Review, vol. 34, pp. 217-220, 1972.

[7] S. Lekhchine, T. Bahi, I. Aadlia, Z. Layate, H. Bouzeria, "Speed control of doubly fed induction motor," Science Direct Journal, 2015.

[8] K. Loukal, L. Benalia, A. Bouguerra, "Speed Control of a Doubly Fed Induction Motor Based on Fuzzy GainAdaptive IP," 16 International Journal of Information Technology and Electrical Engineering, 2012.

[9] Grzegorz Tarchała, "Sliding Mode Speed Control of an Induction Motor Drive Using Time-varying Switching Line", Power Electronics and Drives, vol. 2(37), 2017.

[10] MM. Chaari, M. Soltani and Gossa, "Comparative study between the conventional regulators and fuzzy logic controller: application on the induction machine," International Journal of Sciences and Techniques of Automatic control \& computer engineering IJ-STA, vol. 1(2), pp. 196-212, Dec 2007.

[11] MA. Fnaiech, F. Betin, F. Fnaiech, G. A. Capolino. "Sliding mode control for dual three-phase induction motor drives", IEEE ISIE, Montréal, Québec, Canada, pp. 2281-2285, Jul 2006.

[12] AA. Nasri, A. Hazzab, I. K. Bousserhane, S. Hadjiri, P. Sicard, "Two Wheel Speed Robust Sliding Mode Control for Electrical Vehicle Drive," Serbian Journal of Electrical Engineering, vol. 5(2), pp. 199-216, Nov 2008.

[13] ZZ. Boudjema, A. Meroufel and Y. Djerriri, "Nonlinear control of a doubly fed induction generator for wind energy conversion," Carpathian Journal of Electronic and Computer Engineering, pp. 28-35, 2013.

[14] DD. Kairous and B. Belmadani, "Robust Fuzzy-Second Order Sliding Mode based Direct Power Control for Voltage Source Converter," (IJACSA) International Journal of Advanced Computer Science and Applications, vol. 6(8), 2015.

[15] TT. Ramesh, A. K. Panda, and S. Shiva Kumar, "Fuzzy Logic and Sliding-Mode Speed Control Based Direct Torque and Flux Control Scheme to Improve the Performance of an Induction Motor Drive," International Journal on Electrical Engineering and Informatics, vol. 6(1), Mar 2014.

[16] AA. Boucheta, I. Bousserhane, A. Hazzab, B. Mazari, M. Fellah, "Fuzzy-Sliding Mode Controller for Linear Induction Motor Control," Rev. Roum. Sci. Techn.-Électrotechn. et Énerg., vol. 54(4), pp. 405-414, Bucarest, 2009.

[17] SS. Ardjoun, M. Abid, A. Aissaoui, A. Naceria, "Robust Fuzzy Sliding Mode Control Applied to the Double Fed Induction Machine," International Journal of Circuits, Systems and Signal Processing, vol. 5(4), 2011.

[18] SS. Massoum, A. Bentaallah, A. Massoum, F. Benaimeche, P. Wira, and A. Meroufel, "Fuzzy Sliding Mode Speed Controller for a Vector Controlled Induction Motor," International Journal of Electrical and Computer Engineering vol. 7(6), 2013.

[19] Dj. Cherifi, Y. Miloud, "Speed Sensorless Control of a Doubly Fed Induction Motor Drives using MRAS Estimator," International Journal of Electrical Components and Energy Conversion, VOL. 4(1), PP. 1-12, 2018.

[20] Z. Boudjema, R. Taleb, A. Yahdou, H. Kahal, "High order sliding mode control of a DFIM supplied by two power inverters," Carpathian Journal of Electronic and Computer Engineering, pp. 23-30, 2015. 